Jurnal Health Sains: p-ISSN: 2723-4339 e-ISSN: 2548-1398

Vol. 2, No. 3, Maret 2021

\title{
PENERAPAN BUDAYA KESELAMATAN DAN PERILAKU KESELAMATAN PADA PEKERJA SPUN PILE DI PT. X PLANT CIBITUNG
}

\author{
Ajeng Karima, Herry Koesyanto \\ Universitas Negeri Semarang (UNNES) Jawa Tengah, Indonesia \\ Email: ajengkarimad@students.unnes.ac.id dandhim45ku@yahoo.co.id
}

\begin{tabular}{ll}
\hline ARTIKEL INFO & ABSTRACT \\
\hline Tanggal diterima: 5 Maret 2021 & The average accident data for $2014-2018$ based on the \\
Tanggal direvisi: 15 Maret 2021 & location of the incident $69.75 \%$ occurred in the \\
Tanggal disetujui: 25 Maret 2021 & workplace. According to a survey conxducted by Social \\
Keywords: & Security Administrator of Employment $22 \%$ suggested \\
safety culture; safety behaviour; & promotive assistance related to improved occupational \\
spun pile & safety and health culture. The purpose of this study was \\
& to find out about application of safety culture and safety \\
& behavior in spun pile workers at PT. X Plant Cibitung. \\
& Type of research is descriptive qualitative. The primary \\
& data sources was informants who were determined by \\
& purposive sampling method. Secondary data sources \\
& from literature studies, references and company \\
& documents. Human instruments was research \\
& instruments, interview guides and documentary study \\
& sheets. Data collection techniques with interviews and \\
& documentation study. Data analysis techniques, namely \\
& by reducing data, presenting data and drawing \\
conclusions. The research was conducted in July 2020 at \\
PT. X Plan Cibitung. The results showed that $67.2 \%$ (39 \\
points) were fulfilled, 29.4\% (17 points) were not \\
fulfilled, and 3.4\% (2 points) were not fulfilled from the \\
safety culture factors and the value of safe behavior was \\
87,2\% got good categoric. The conclusion of this \\
research there is implementation of safety culture and \\
safety behavior among spun pile workers at PT. X Plant \\
Cibitung.
\end{tabular}

\begin{abstract}
ABSTRAK
Rata-rata data kecelakaan tahun 2014 - 2018 berdasarkan lokasi kejadian 69,75\% terjadi di dalam tempat kerja. Menurut survei yang telah dilakukan oleh BPJS Ketenagakerjaan 22\% mengusulkan bantuan promotive terkait peningkatan budaya keselamatan dan kesehatan kerja. Tujuan penelitian ini untuk mengetahui penerapan budaya keselamatan (safety culture) dan perilaku keselamatan (safety behavior) pada pekerja spun pile di PT. X Plant Cibitung. Jenis penelitian kualitatif deskriptif. Sumber data primer adalah informan yang ditentukan dengan metode purposive sampling. Sumber data sekunder dari studi kepustakaan, referensi dan dokumen perusahaan. Instumen penelitian yaitu
\end{abstract}


human instrument, pedoman wawancara dan lembar studi dokumentasi. Teknik pengambilan data dengan wawancara dan studi dokumentasi. Teknik analisis data yakni dengan mereduksi data, penyajian data dan penarikan kesimpulan. Penelitian dilaksanakan pada bulan Juli-Agustus 2020 di PT. X Plant Cibitung. Hasil penelitian menunjukkan sebanyak $67,2 \%$ (39 poin) terpenuhi, 29,4\% (17 poin) tidak sesuai, dan 3,4\% (2 poin) tidak terpenuhi dari indicator budaya keselamatan serta nilai perilaku aman sebesar $87,2 \%$ dengan kategori

Kata Kunci:

budaya keselamatan; perilaku keselamatan; spun pile baik. Simpulan penelitian ini adalah adanya penerapan budaya keselamatan dan perilaku keselamatn pada pekerja spun pile di PT.X Plant Cibitung.

Coresponden Author:

Email: ajengkarimad@students.unnes.ac.id Artikel dengan akses terbuka dibawah lisensi

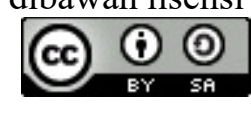

\section{Pendahuluan}

Kecelakaan kerja tidak hanya menimbulkan korban jiwa dan kerugian materi bagi pekerja serta pengusaha, tetapi dapat mengganggu proses produksi secara menyeluruh, merusak lingkungan, dan berdampak pada masyarakat luas (Fridayanti \& Kusumasmoro, 2016).

$$
\text { Berdasarkan data BPJS }
$$

Ketenagakerjaan, jumlah kecelakaan kerja di Indonesia pada tahun 2014 - 2018 berturutturut sebanyak 105.182 kasu0073, 110.272 kasus, 101.367 kasus, 123.041 kasus, 173.105 kasus. Rata-rata data kecelakaan selama 5 tahun terakhir tahun 2014 - 2018 berdasarkan lokasi kejadian $69,75 \%$ terjadi di dalam tempat kerja. Menurut survey yang telah dilakukan oleh BPJS Ketenagakerjaan terdapat 807 responden atau $22 \%$ mengusulkan bantuan promotive terkait peningkatan budaya keselamatan dan kesehatan kerja (Ketenagakerjaan, 2019).

Penyebab kecelakaan secara umum disebabkan oleh dua hal yaitu perilaku kerja yang tidak aman (unsafe action) dan kondisi kerja yang tidak aman (unsafe condition) (Anizar, 2009). Berdasarkan rata-rata data kecelakaan tahun 2014 s.d 2018 BPJS Ketenagakerjaan penyebab kecelakaan yang disebabkan kondisi berbahaya (unsafe condition) 57,49\% karena pengamanan yang tidak sempurna, $16,37 \%$ adanya prosedur/pengaturan yang tidak aman dan $10,96 \%$ adanya gerakan (perputaran) sedangkan penyebab kecelakaan yang disebabkan tindakan bahaya 24,40\% karena posisi bekerja tidak aman, 19,79\% mengalami gangguan perhatian dan konsentrasi dan 13,66\% karena lalai (Ketenagakerjaan, 2019).

Berdasarkan penelitian (Andi et al., 2005) bahwa budaya keselamatan kerja berpengaruh terhadap perilaku pekerja konstruksi, melalui faktor-faktor komitmen manajemen, peraturan dan prosedur keselamatan kerja, komunikasi, dan keterlibatan pekerja sedangkan faktor keterlibatan dan lingkungan kerja tidak berpengaruh.

Berdasarkan penelitian (Suyono \& Nawawinetu 2013) menunjukkan bahwa faktor pembentuk budaya keselamatan dengan kuat hubungan yang lemah terhadap safety behavior yaitu komitmen manajemen, peraturan dan prosedur K3, dan keterlibatan pekerja. Faktor pembentuk budaya keselamatan yang memiliki hubungan kuat dengan safety behavior yaitu komunikasi (c = 
$0,414)$ dan lingkungan sosial pekerja $(\mathrm{c}=$ $0,477)$.

Menurut penelitian (Kania et al., 2016) hasil analisis menunjukan bahwa nilai dari budaya kesehatan dan keselamatan kerja dari para pekerja kargo di gudang berada di atas index average 5.0. Hal ini berarti bahwa secara umum masing-masing pekerja berada pada level nilai K3 yang moderat. Sedangkan hasil analisis faktor telah mengurangi 19 faktor menjadi 11 faktor yang mempengaruhi budaya K3 yakni Komitmen terhadap keselamatan, Peraturan dan prosedur keselamatan, Isu-isu keselamatan terbaru, Kepraktisan, Kepedulian terhadap keselamatan, Keterlibatan pekerja, Pelaporan, Kesadaran terhadap keselamatan diri, Pengetahuan tentang keselamatan, Fasiltas dan peralatan kerja dan Pengalokasian waktu

Menurut penelitian (Somad 2013) budaya K3 (safety culture) didefinisikan sebagai nilai-nilai dan kepercayaan bersama yang berinteraksi dengan struktur organisasi dan sistem pengendalian untuk menghasilkan norma-norma perilaku. Setiap anggota organisasi berperilaku selaras dengan sasaran untuk menghindarikan terjadinya cidera pada manusia, meningkatkan komitmen manajemen, meningkatkan kepuasan bekerja, dan mengurangi keluhan fisik.

Menurut (Geller 2001) terdapat tiga faktor dalam total safety culutre, yaitu (1) Enviroment factors adalah faktor lingkungan yang mempengaruhi keselamatan di tempat kerja, termasuk perlengkapan, peralatan, perawatan mesin, suhu dan standar operasional prosedur. (2) Person factors adalah faktor individu yang mempengaruhi keselamatan ditempat kerja, termasuk sikap dan keyakinan yang berupa pengetahuan, keterampilan, kemampuan, intelegensi dan motivasi, serta kepribadian. (3) Behavior factors adalah faktor perilaku yang mempengaruhi keselamatan ditempat kerja, termasuk pelatihan, komunikasi, peduli secara aktif.

Menurut (Andi et al., 2005) pada penelitiannya mengenai budaya keselamatan kerja, terdapat lima indikator yang berhubungan dengan budaya keselamatan kerja di perusahaan/industri. Kelima indikator tersebut yaitu komitmen top manajeman, peraturan dan prosedur keselamatan, komunikasi pekerja, kompetensi pekerja, dan keterlibatan pekerja.

Perilaku Keselamatan (safety behavior) adalah perilaku kerja yang relevan dengan keselamatan dapat dikonseptualisasikan dengan cara yang sama dengan perilakuperilaku kerja lain yang membentuk perilaku kerja. Perilaku keselamatan merupakan aplikasi dari perilaku tugas yang ada di tempat kerja (Griffin \& Neal, 2000).

Menurut (Tarwaka 2015) behavior based safety adalah perilaku keselamatan manusia di area kerja dalam mengidentifikasi bahaya serta menilai potensi risiko yang timbul hingga dapat diterima dalam melakukan pekerjaan yang berinteraksi dengan aktivitas, produk, dan jasa yang dilakukan.

Menurut penelitian (Cooper, 2000) mengidentifikasi adanya tujuh kriteria yang sangat peting bagi pelaksanaan behaviour based safety, yaitu (1) Melibatkan partisipasi karyawan yang bersangkutan; Memusatkan perhatian pada unsafe behavior yang spesifik; (3) Didasarkan pada data hasil observasi; (4) Proses pembuatan keputusan berdasarkan data; (5) Melibatkan intervensi secara sistematis dan observasional; (6) Menitikberatkan pada umpan balik terhadap perilaku; (7) Membutuhkan dukungan dukungan dari manajer.

Rumus untuk menghitung perilaku aman didasarkan pada total individu dari kedua kolom aman dan tidak aman dan membagikan jumlah total ke dalam jumlah 
perilaku aman yang dircatat dan mengalikan dengan seratus (Tarwaka, 2015).

$\begin{array}{lll}\% & \text { Perilaku } & \text { Aman } \\ & \text { Total skor/aman' } & \end{array}$

Persentase perilaku aman yang didapat berdasarkan pada hasil perhitungan dengan rumus tersebut di atas, selanjutnya akan dikategorikan menurut (Geller 2001) dalam berdasarkan 3 kategori yang meliputi :

1. Kategor baik jika persentase $\geq 85 \%$.

2. Kategori cukup baik jika persentase antara $60 \%-84,9 \%$.

3. Kategori kurang baik jika persentase $\leq$ $59,9 \%$.

Beberapa hal yang membedakan penelitian ini dengan penelitian-penelitian sebelumnya adalah lokasi dan waktu penelitian ini berbeda dari penelitian sebelumnya. Tujuan penelitian ini untuk mengetahui penerapan budaya keselamatan (safety culture) dan perilaku keselamatan (safety behavior) pada pekerja spun pile di PT. X Plant Cibitung.

\section{Metode Penelitian}

Jenis penelitian ini adalah penelitian kualitatif dengan metode deskriptif. Fokus masalah dalam penelitian ini adalah melihat bagaimana penerapan budaya keselamatan (safety culture) dan perilaku keselamatan (safety behavior) pada pekerja spun pile di PT. X Plant Cibitung. Penerapan budaya keselamatan (safety culture) dilihat dari komitmen manajeman, peraturan dan prosedur keselamatan, komunikasi pekerja, kompetensi pekerja, keterlibatan pekerja serta perilaku keselamatan dilihat dari perilaku pekerja potensi bahaya tinggi, perilaku ketika persiapan kerja, perilaku aman pekerja, perilaku operator, perilaku pelaksana,dan perilaku APD \& housekeeping. Penelitian dilaksanakan pada bulan Juli 2020.

Sumber infromasi dalam penelitian ini adalah dari data primer yang meliputi wawancara serta data sekunde yang digunakan sebagai pelengkap dan penunjang data primer. Data primer diperoleh dari hasil wawancara terhadap informan. Informan utama dalam penelitian ini adalah Health Safety and Environment (HSE) Representative Plant, Kepala Health Safety and Environment (HSE), Pekerja Spun Pile serta informan triangulasi pada penelitian ini yaitu Kepala Plant PT. X, Pelaksana Spun Pile, Supervisior Spun Pile. Informan dalam peneltian ini ditentukan menggunakan teknik purposive sampling. Data sekunder dalam penelitian ini didapatkan dari studi kepustakaan dan doukumen-dokumen PT.X.

Instrumen yang digunakan dalam penelitian ini yaitu human instrument, pedoman wawancara dengan bantuan alat seperti buku catatan, alat perekam dan kamera serta lembar studi dokumentasi. Teknik pengambilan data pada penelitian ini yait dengan wawancara yang termasuk dalam kategori in-dept-interview dan dokumentsi dengan mempelajari dokumen-dokumen perusahaan.

Pemerikasaan keabsahan data dalam penelitian ini dengan menggunakan triangulasi teknik dan triangulasi sumber. Triangulasi tekni triangulasi teknik dilakukan dengan cara membandingkan data yang diperoleh dari wawancara dengan dan hasil dokumentasi. Triangulasi sumber dengan membandingkan dan mengecek balik derajat kepercayaan suatu informasi yang diperoleh melalui waktu dan alat yang berbeda. Triangulasi dengan sumber akan dilakukan dengan cara: (1) Membandingkan data hasil pengamatan dengan data hasil wawancara; (2) Membandingkan data hasil wawancara informan satu dengan informan lainnya; (3) Membandingkan hasil wawancara dengan isi suatu dokumen yang berkaitan.

Teknik analisis data yang digunakan terdiri dari: (1) Reduksi data, dalam penelitian ini melalui wawancara dan studi 
dokumentasi; (2) Penyajian data, dalam penelitian ini dengan membandingkan antara informasi yang diperoleh dengan studi dokumentasi atau antar informan kemudian disajikan dalam bentuk table; (3) Verifikasi (penarikan kesimpulan).

\section{Hasil dan Pembahasan}

Penelitian ini dilaksanakan di PT. X Plan Cibitung pada pekerja unit produksi spun pile. PT. X sebelumnya merupakan divisi precast PT. Y. seiring dengan pertumbuhan PT. Y yang semakin pesat maka pada Januari 2018, PT. Y melepaskan divisi precast menjadi anak perusahaan dengan nama PT. X. Kemudian, PT.X berfokus pada bisnis utamanya adalah produksi beton pracetak, termasuk pemasangan (instal) pada proyek yang sedang dikerjakan. Jangkauan wilayah pasar meliputi seluruh wilayah Indonesia dengan beberapa plan yang berlokasi di Cibitung, Cikarang, karawang, Cilacap, Surabaya dan Gresik.

Informan dalam penelitian ini berjumlah 5 reponden. Karakteristik responden berdasarkan usia sebanyak 2 respoden (40\%) berusia kurang dari 30 tahun dan 3 responden $(60 \%)$ berusia lebih dari 30 tahun. Karakteristik resonden berdasarkan Jenis Kelamin sebanyak 5 responden $(100 \%)$ berjenis kelamin laki-laki. Karakteristik reponden berdasarkan tingkat pendidikan sebanyak 3 responden $(60 \%)$ tingkat pendidikan terakhir yakni SMA/SMK sederajat dan 2 responden (40\%) Sarjana Strata 1.
Tabel 1

Distribusi Hasil Budava Keselamatan

\begin{tabular}{|c|c|c|c|c|c|c|}
\hline \multirow{3}{*}{ Parameter } & \multicolumn{6}{|c|}{ Kesesuaian } \\
\hline & \multicolumn{2}{|c|}{ Sesuai } & \multicolumn{2}{|c|}{$\begin{array}{c}\text { Tidak } \\
\text { Sesuai } \\
\end{array}$} & \multicolumn{2}{|c|}{ Tidak Ada } \\
\hline & $\mathbf{N}$ & $\%$ & $\mathbf{N}$ & $\%$ & $\underline{\mathbf{N}}$ & $\%$ \\
\hline $\begin{array}{l}\text { Komitmen } \\
\text { Manajeman }\end{array}$ & 12 & 66,7 & 5 & 27,8 & 1 & 5,5 \\
\hline $\begin{array}{l}\text { Peraturan dan } \\
\text { Prosedur }\end{array}$ & 9 & 69,2 & 3 & 23,1 & 1 & 7,7 \\
\hline Komunikasi & 8 & 80 & 1 & 10 & 1 & 10 \\
\hline $\begin{array}{l}\text { Kompetensi } \\
\text { Pekerja }\end{array}$ & 6 & 75 & 2 & 25 & - & - \\
\hline $\begin{array}{l}\text { Keterlibatan } \\
\text { Pekerja }\end{array}$ & 5 & 55,6 & 2 & 22,2 & 2 & 22,2 \\
\hline
\end{tabular}

Penerapan budaya keselamatan (safety culture) pada pekerja spun pile di PT. X Plan Cibitung dalam peneliti ini terdapat lima faktor berdasarkan penelitian (Andi et al., 2005) dan Widiyanti \& Koesyanto (2016). Lima faktor yang menjadi parameter dalam penelitian ini yaitu komitmen manajeman, peraturan dan prosedur, komunikasi, kompetensi pekerja, keterlibatan pekerja. Jumlah indikator dari seluruh parameter dalam penelitian ini yaitu 20 indikator dan 58 poin yang terdiri atas: 5 indikator dan 18 poin komitmen manajeman; 5 indikator dan 13 poin peraturan dan prosedur; 4 indikator dan 10 poin komunikasi; 3 indikator dan 8 poin kompetensi pekerja; 3 indikator dan 9 poin keterlibatan pekerja.

Hasil penilaian penerapan budaya keselamatan (safety culture) pada pekerja spun pile PT. X Plan Cibitung diperoleh hasil sebanyak $67,2 \%$ (39 poin) terpenuhi, $29,4 \%$ (17 poin) tidak sesuai, dan $3,4 \%$ (2 poin) tidak terpenuhi. Faktor komitmen manajeman sebanyak $72 \%$ (13 poin) terpenuhi, 28\% (5 poin) tidak sesuai; faktor peraturan dan prosedur $\mathrm{K} 3$ sebanyak $77 \% \quad(10$ poin $)$ terpenuhi, 23\% (3 poin) tidak sesuai; faktor komunikasi sebanyak $80 \%$ ( 8 poin) terpenuhi, $10 \%$ (1 poin) tidak sesuai dan $10 \%$ (1 poin) tidak terpenuhi; faktor kompetensi pekerja sebanyak $75 \%$ (6 poin) terpenuhi dan $25 \%$ ( 2 poin) tidak sesuai; faktor keterlibatan pekerja sebanyaj $55,6 \%$ (5 poin) terpenuhi, $22,2 \%$ (2 
poin) tidak sesuai dan $22,2 \%$ ( 2 poin) tidak terpenuhi.

Berdasarkan hasil penelitian faktor komitmen manajeman sebanyak 66,7\% (12 poin) terpenuhi, $27,8 \%$ (5 poin) tidak sesuai dan $5,5 \%$ (1 poin) tidak terpenuhi. Faktor komitmen manajeman terdiri dari 5 indikator dengan hasi sebaai berikut: (1) indikator perlengkapan K3 terdapat 2 poin sebanyak $100 \%$ (2 poin) terpenuhi dengan sesuai, (2) indicator pelatihan $\mathrm{K} 3$ terdapat 3 poin sebanyak $100 \%$ (3 poin) terpenuhi dengan sesuai, (3) indikator pengawasan terdapat 6 poin sebanyak $83,3 \%$ (5 poin) terpenuhi dengan sesuai dan $16,7 \%$ (1 poin) tidak sesuai, (4) indicator tindakan reaktif bila terjadi kecelakaan kerja terdapat 3 poin sebanyak $66,7 \%$ ( 2 poin) terpenuhi dengan sesuai dan $33,3 \%$ (1 poin) tidak sesuai, (5) indicator upaya peningkatan kinerja K3 terdapat 4 poin sebanyak $25 \%$ (1 poin) terpenuhi dengan sesuai dan $75 \%$ (3 poin) tidak sesuai.

Hasil penelitian ini didukung berdasarkan hasil penelitian (Kania et al., 2016) terkait analisis faktor budaya keselamatan dan kesehatan kerja (K3) komitmen manajeman memiliki skor 5,94 yang artinya secara umum keseluruhan individu memiliki nilai yang cukup. Penelitian (Sutrisno et al. 2017) faktor komitmen manajeman secara umum mendapatkan skor 4,06 dan secara spesifik mendapatkan skor 4,17 namun tidak berpengaruh terhadap perilaku keselamatan yang dapat menyebabkan kecelakaan/ insiden/nearmiss. Penelitian (Khoiri, 2010) didapatkan bahwa komitmen top manajeman berpengaruh untuk meningkatkan perilaku aman bagi pekerja radiasi di rumah sakit . Penelitian (Suyono \& Nawawinetu, 2013) terdapat $76,7 \%$ responden tergolong baik untuk faktor komitmen manajeman namun tidak ada hubungan terhadap perilaku keselamatan. Penelitian lain didapatkan hasil bahwa terdapat hubungan yang bermakna komitmen manajeman terhadap kecelakaan kerja (Andini 2017) . Komitmen manajeman mendukung budaya perilaku keselamatan di rumah sakit (Ardi et al. 2018). Komitemen manajeman memliki pengaruh searah terhadap kinerja proyek konstruksi (Christina et al., 2012). Ada hubungan yang bermakna antara komitmen manajeman dengan perilaku keselamatan (Harnanda, 2017; Nurhayati, 2018; Utami, 2016).

Komitmen manajeman berperan penting agar suatu implementasi budaya K3 bisa berjalan dengan baik. Komitmne manajeman merupakan hal yang paling mendasar dan paling penting dalam menggerakkan partisipasi pekerja terhadap pemenuhan perilaku kerja aman unutk mencapai budaya K3 unggul. Komitmen manajmean yang tinggi akan menjamin aspek K3 bisa terpadu dengan baik dalam struktur organisasi maupun alokasi sumber daya dan memprioritaskan K3 dalam setiap kegiatan operasi. Perusahaan yang memiliki budaya keselamatan yang lebih positif memiliki praktik manajemen K3 yang jauh lebih baik, budaya keselamatan memperngaruhi manajemen K3 (Nordlöf et al., 2017). Budaya keselamatan dan sistem manajemen keselamatan cukup berhubungan, budaya keselamatan secara langsung mempengaruhi sistem manajemen K3 (Jiang et al., 2019). Top management pada perusahaan yang telah mencapai budaya K3 unggul sudah benarbenaar menyadari bahwa biaya, produktifitas, kualitas dan K3 adalah seiring sejalan (Somad, 2013). Penekanan manajemen terhadap pentingnya keselamatan berdampak positif pada budaya keselamatan (Aburumman et al., 2019).

Menurut (Andi et al., 2005) komitmem manajemen sebagai salah satu faktor budaya keselamatan mempengaruhi perilaku pekerja. Salah stau hal yang penting yang ditemukan dari hasil analisis penelitian (Andi et al., 
2005) adalah faktor komitmen manajemen merupakan penggerak utama dari budaya keselamatan kerja. Komitmen manajemen dapat diwujudkan dengan memberikan perlengkapan keselamatan kerja, mengadakan pengawasan terhadap keselamatan kerja, mengadakan oengawasan terhadap keselamatan kerja dan yang terutama membentuk peraturan dan prosedur keselamtan kerja yang mudah dimengeri dan pekerja tidak mengalami kesulitan dalam melaksanakan peraturan dan prosedur tersebut (Andi et al., 2005).

Berdasarkan penelitian (Khoiri 2010) komitmem top manajemen tidak berpengaruh langsung terhadap perilaku K3 namun merupakan faktor utama dalam mempengaruhi budaya keselamatan. Maka, hendaknya pihak manajemen puncak memandang keselamatan sebagai bagian tidak terpisahkan dari strategi untuk pengendalian resiko (Khoiri, 2010). Hasil penelitian (Nurhayati 2018), menjelaskan bahwa respon pekerja terhadap komitmen manajemen tergolong baik terhadap bentuk komitmen manajemen mengenai mutu serta kesehatan dan keselamatan kerja. Upaya manajemen untuk mempertahankan respon pekerja yang tergolong baik terhadap komitmen manajemen yaitu lebih aktif dalam K3 yang ditunjukkan dalam memberikan keteladanan K3 yang lebih baik dan melibatkan diri dalam setiap kegiatan (Nurhayati, 2018). Komitmen manajemen menjadi salah satu faktor budaya keselamatan yang memiliki dampak paling besar terhadap budaya keselamatan (Tehrani et al., 2019).

Berdasarkan hasil penelitian faktor peraturan dan prosedur sebanyak $77 \%$ (10 poin) terpenuhi, $23 \%$ (3 poin) tidak sesuai. Faktor peraturan dan prosedur terdiri dari 5 indikator yaitu (1) indicator pentingnya peraturan dan prosedur $\mathrm{K} 3$ terdapat 3 poin sebanyak $100 \%$ (3 poin) terpenuhi dengan sesuai; (2) indicator kekonsistenan peraturan dan prosedur $\mathrm{K} 3$ terdapat 4 poin sebanyak $50 \%$ ( 2 poin) terpenuhi dengan sesuai dan $50 \%$ (2 poin) terpenuhi tidak sesuai; (3) indicator sosialisasi peraturan dan prosedur $\mathrm{K} 3$ terdapat 3 poin sebanyak $63,3 \%$ (2 poin) terpenuhi dengan sesuai dan $33,7 \%$ (1 poin) tidak sesuai; (4) indicator review/update peraturan dan prosedur $\mathrm{K} 3$ terdapat 2 poin sebanyak $50 \%$ (1 poin) terpenuhi dengan sesuai dan $50 \%$ (1 poin) tidak sesuai, (5) indicator sanksi pelanggaran peraturan dan prosedur K3 terdapat 1 poin sebanyak $100 \%$ (1 poin) terpenuhi dengan sesuai.

Hasil penelitian ini didukung berdasarkan hasil penelitian (Kania et al., 2016) terkait analisis faktor budaya keselamatan dan kesehatan kerja (K3) peraturan dan prosedur keselamatan memiliki skor 6,54 yang artinya secara umum keseluruhan individu memiliki nilai yang cukup. Penelitian (Sutrisno et al., 2017) faktor peraturan dan prosedur mendapatkan skor 3,69 namun tidak berpengaruh terhadap perilaku keselamatan yang dapat menyebabkan kecelakaan/insiden/nearmiss. Pada penelitian (Suyono \& Nawawinetu, 2013) terdapat $76,7 \%$ responden tergolong baik untuk faktor Peraturan dan Prosedur namun tidak ada hubungan terhadap perilaku keselamatan. Penelitian (Andini (2017), Aprilia (2017) dan Utami (2016)) menunjukan bahwa peraturan dan prosedur terdapat hubungan dengan perilaku keselamatan. Berdasarkan penelitian (Christina et al. 2012) peraturan dan prosedur memiliki pengaruh yang cukup signifikan terhadap kinerja proyek.

Cara lain untuk mengurangi bahaya adalah dengan menyediakan prosedur $\mathrm{K} 3$. Peraturan dan prosedur dirancang untuk menstandarisasi cara kerja yang bertujuan untuk meminimasi potensi tidak aman pada saat dan sesudah melakukan pekerjaan yang berpotensi menimbulkan cedera karena terjadinya kecelakaan (Somad, 2013). 
Budaya K3 dapat diciptakan apabila adanya pola pikir/mindset baik dari manajemen maupun pekerja tentang pentingnya peraturan dan prosedur $\mathrm{K} 3$, adanya konsistensi terhadap penerapan peraturan dan prosedur $\mathrm{K} 3$, adanya penyusunan peraturan dan prosedur K3 yang diterapkan, pihak manajemen mensosialisasikan peraturan dan prosedur K3 yang diterapkan di perusahaan kepada seluruh pekerja, adanya pembaruan (review/update) peraturan dan prosedur K3 untuk menyesuaikan dengan lingkungan kerja, serta ada tidaknya sanksi yang diberikan ketika terjadi pelanggaran terhadap peraturan dan prosedur K3 tersebut (Andi et al., 2005; Christina et al., 2012)

Berdasarkan hasil penelitian faktor komunikasi sebanyak $80 \%$ ( 8 poin) terpenuhi, $10 \%$ ( 1 poin) tidak sesuai dan $10 \%$ (1 poin) tidak terpenuhi. Faktor komunikasi terdiri dari 4 indikator yaitu (1) indicator pemberian informasi K3 terdapat 3 poin sebanyak $67,3 \%$ ( 2 poin) terpenuhi dengan sesuai dan $33,3 \%$ (1 poin) tidak sesuai, (2) indicator pemberian informasi kecelakaan kerja terdapat 4 poin sebanyak $100 \%$ (4 poin) terpenuhi dengan sesuai, (3) indicator komunikasi dengan pihak manajerial terdapat 1 poin sebanyak $100 \%$ (1 poin) terpenuhi dengan sesuai, (4) indicator komunikasi dengan pekerja terdapat 2 poin sebanyak $50 \%$ (1 poin) terpenuhi dengan sesuai dan $50 \%$ (1 poin) tidak terpenuhi.

Hasil penelitian ini didukung berdasarkan hasil penelitian (Kania et al., 2016) terkait analisis faktor budaya keselamatan dan kesehatan kerja (K3) komunikasi memiliki skor 5,87 yang artinya secara umum keseluruhan individu memiliki nilai yang cukup. Penelitian (Sutrisno et al. 2017) faktor komunikasi mendapatkan skor 3,78 berpengaruh terhadap perilaku keselamatan sehingga dapat menyebabkan kecelakaan/ insiden/nearmiss. Penelitian (Suyono \& Nawawinetu 2013) terdapat
$78,1 \%$ responden tergolong baik terhadap pelaksanaan komunikasi dan memiliki hubungan yang kuat terhadap perilaku keselamatan. Hasil penelitian (Andi et al., (2005), (Khoiri 2010) menunjukan bahwa komunikasi berpengaruh terhadap perilaku pekerja konstruksi. Komunikasi memiliki hubungan yang bermakna dengan perilaku keselamatan (Nurhayati, 2018; Utami, 2016). Komunikasi memiliki pengaruh yang cukup signifikan terhadap kinerja proyek (Christina et al., 2012). namun penelitian Pangaribuan (2016) mengungkapkan bahwa komunikasi merupakan faktor budaya K3 yang memiliki hubungan signifikan dengan kinerja keselamatan. Penelitian Aprilia (2017) menunjukkan bahwa tidak terdapat hubungan antara komunikasi $\mathrm{K} 3$ dengan perilaku tidak aman (Aprilia, 2017).

Organisasi perusahaan yang memiliki suatu budaya K3 positif biasanya ditandai dengan adanya komunikasi yang dibangun atas dasar saling percaya antara semua pihak, dengan berbagai persepsi terhadap hal-hal penting tentang $\mathrm{K} 3$ dan dengan membangun kepercayaan dalam keberhasilan dari suatu upaya pencegahan kecelakaan dan penyakit akibat kerja (Tarwaka, 2015).

Program keselamatan kerja hendaknya didukung oleh sistem manajemen informasi yang baik dalam hal pengumpulan dan penyampaian informasi, meliputi adanya jalur informasi yang baik dari pihak manajemen kepada para pekerja maupun sebaliknya dari pekerja tentang kondisi tidak aman kepada pihak manajemen. Informasi terbaru sangatlah penting, terutama yang berhubungan dengan peraturan dan prosedur keselamatan kerja dan keadaan bahaya di lingkungan kerja (Andi et al., 2005).

Peraturan Pemerintah Republik Indonesia Nomor 50 tahun 2012 tentang Penerapan Sistem Manajemen Keselamatan dan Kesehatan Kerja, pasal 13 ayat (1) menjelaskan bahwa prosedur informasi harus 
memberikan jaminan bahwa informasi $\mathrm{K} 3$ dikomunikasikan kepada semua pihak dalam perusahaan dan pihak terkait di luar perusahaan (pemerintah).

Peraturan Menteri Tenaga Kerja Nomor PER.05/MEN/1996 tentang sistem manajemen Keselamatan dan Kesehatan Kerja pada poin kegiatan pendukung dengan sub komunikasi menyatakan bahwa perusahan harus mempunyai prosedur untuk menjamin bahwa informasi keselamatan dan kesehatan kerja terbaru dikomunikasikan ke semua pihak dalam perusahaan. Berdasarkan penelitian komunikasi berpengaruh terhadap perilaku keselamatan (Sutrisno et al., 2017). Komunikasi menjadi salah satu faktor budaya keselamatan yang memiliki dampak paling besar terhadap budaya keselamatan (Tehrani et al., 2019).

Berdasarkan hasil penelitian faktor kompetensi pekerja sebanyak $75 \%$ (6 poin) terpenuhi dan $25 \%$ (2 poin) tidak sesuai. Faktor komptensi pekerja memiliki 3 indikator yaitu (1) indicator pengetahuan pekerja mengenai resiko bahaya terdapat 4 poin sebanyak $100 \%$ (4 poin) terpenuhi dengan sesuai, (2) indicator kemampuan pekerja memenuhi peraturan dan prosedur K3 terdapat 2 poin sebanyak $50 \%$ (1 poin) terpenuhi dengan sesuai dan $50 \%$ (1 poin) terpenuhi tidak sesuai, (3) indicator upaya peningkatan kompetensi pekerja mengenai K3 terdapat 2 poin sebanyak $50 \%$ ( 1 poin) terpenuhi dengan sesuai dan $50 \%$ (1 poin) terpenuhi tidak sesuai.

Kompetensi pekerja seringkali
berhubungan
pengetahuan, ketrampilan, dan pengalaman kerja. Mohamed (2002) dalam (Andi et al., 2005) menjabarkan kompetensi pekerja secara menyeluruh sebagai pengetahuan, pengertian, dan tanggung jawab pekerja terhadap pekerjaannya, maupun pengetahuan terhadap risiko dan bahaya yang mengancam pekerja dalam melakukan pekerjaannya.
Hasil penelitian ini didukung berdasarkan hasil dari penelitian (Khoiri, 2010) yang menjelaskan bahwa kompetensi sangat berpengaruh untuk meningkatkan perilaku mana bagi pekerja radiasi di rumah sakit. Hasil lain menyebutkan bahwa kompetensi mendukung pelaksanaan budaya perilaku keselamatan di rumah sakit (Ardi et al., 2018). Berdasarkan penelitian Christina et al. (2012) kompetesi pekerja memiliki pengaruh terhadap kinerja proyek (Christina et al., 2012). Namun hsil penelitian ini tidak sejalan denga hasil penelitian Sutrisno et al. (2017) yang menyatakan bahwa faktor kompetensi mendapatkan skor 4,05 namun tidak berpengaruh terhadap perilaku keselamatan yang dapat menyebabkan kecelakaan/insiden/nearmiss.

Berdasarkan hasil penelitian faktor keterlibatan pekerja sebanyak 45\% (4 poin) terpenuhi, 33\% (3 poin) tidak sesuai dan $22,2 \%$ (2 poin) tidak terpenui. Faktor keterlibatan pekerja memiliki 3 indikator yaitu (1) indicator keterlibatan pekerja dalam penyampaian informasi $\mathrm{K} 3$ terdapat 2 poin sebanyak $100 \%$ (2 poin) tidak sesuai, (2) indicator penyusunan program $\mathrm{K} 3$ terdapat 4 poin sebanyak $75 \%$ ( 3 poin) terpenuhi dengan sesuai dan $25 \%$ (1 poin) tidak terpenuhi, (3) indicator keterlibatan dalam pelaporan kecelakaan kerja atau kondisi atau perilaku berbahaya terdapat 3 poin sebanyak $33,3 \%$ (1 poin) terpenuhi dengan sesuai kemudian $33,3 \%$ (1 poin) terpenuhi tidak sesuai dan $33,3 \%$ (1 poin) tidak terpenuhi.

Keterlibatan pekerja secara langsung dalam pelaksanaan program keselamatan kerja dapat mewujudkan perilaku aman di tempat kerja, sehingga budaya K3 yang diterapkan di perusahaan berjalan sesuai tujuan. Faktor dari terciptanya budaya K3 salah satunya yaitu adanya keterlibatan pekerja dalam kegiatan mengenai K3. Keterlibatan pekerja tersebut diantaranya berupa keterlibatan dalam penyampaian 
informasi mengenai $\mathrm{K} 3$, keterlibatan dalam penyusunan program $\mathrm{K} 3$, keterlibatan dalam pelaporan kecelakaan kerja/kondisi berbahaya (Andi et al., 2005; Christina et al., 2012). Keterlibatan pekerja secara positif berhubungan dengan kepatuhan dan partisipasi keselamatan (Shehu Mashi et al., 2018).

Hasil penelitian ini didukung berdasarkan hasil penelitian (Kania et al., 2016) terkait analisis faktor budaya keselamatan dan kesehatan kerja (K3) keterlibatan pekerja memiliki skor 5,69 yang artinya secara umum keseluruhan individu memiliki nilai yang cukup. Penelitian (Sutrisno et al. 2017) faktor keterlibatan mendapatkan skor 3,89 dan berpengaruh terhadap perilaku keselamatan yang dapat menyebabkan kecelakaan/insiden/nearmiss. Penelitian (Suyono \& Nawawinetu, 2013) terdapat $52,1 \%$ responden tergolong cukup terhadap dalam keterlibatan pekerja dan tidak ada hubungan terhadap perilaku keselamatan. Penelitian lain juga menunjukan hasil bahwa keterlibatan pekerja tidak terdapat hubungan antara keterlibatan pekerja dengan perilaku tidak aman (Aprilia, 2017). Berdasarkan penelitian Selain itu, berdasarkan penelitian Khoiri (2010) didapatkan hasil bahwa keterlibatan pekerja sangat berpengaruh untuk meningkatkan perilaku aman bagi pekerja radiasirumah sakit. Hasil serupa juga ditunjukan oleh penelitian Ardi et al. (2018) bahwa keterlibatan karyawan mendukung pelaksanaan budaya keselamatan di rumah sakit. Berdasarkan penelitian Christina et al. (2012) menunjukan hasil bahwa keterlibatan pekerja memiliki pengaruh yang cukup signifikan terhadaap kinerja proyek konstruksi. Penelitian lain menunjukan bahwa keterlibatan pekerja memiliki hububungan dengan perilaku keselamatan (Nurhayati, 2018).

Berdasarkan penelitian diperoleh hasil penerapan perilaku keselamatan (safety behaviour) pekerja spun pile PT. X Plant Cibitung yaitu secara keseluruhan terdapat 47 poin sebanyak $87,2 \%$ (41 poin) aman dan $12,8 \%$ (6 poin) tidak aman untuk indikator perilaku pekerjaan potensi bahaya tinggi terdapat 4 poin sebanyak $75 \%$ (3 poin) terpenuhi dengan aman dan 25\% (1 poin) tidak aman, indikator perilaku ketika persiapan kerta terdapat 4 poin sebanyak $100 \%$ (4 poin) terpenuhi secara aman, indikator perilaku aman pekerja terdapat 9 poin sebanyak $100 \%$ (9 poin) terpenuhi dengan aman, indikator perilaku operator terdapat 11 poin sebanyak $91 \%$ (10 poin) terpenuhi secara aman dan 9\% (1 poin) tidak aman, indikator perilaku pelaksana terdapat 9 poin sebanyak $100 \%$ ( 9 poin) terpenuhi secara aman, indikator perilaku terhadap penggunaan APD dan Housekeeping terdapat 10 poin sebanyak $60 \%$ (6 poin) terpenuhi dengan aman dan $40 \%$ tidak aman.

Tabel 2

Distribusi Hasil Penerapan Perilaku Keselamatan

\begin{tabular}{lcccc}
\hline \multirow{2}{*}{\multicolumn{1}{c}{ Indikator }} & \multicolumn{4}{c}{ Kesesuaian } \\
\cline { 2 - 5 } & \multicolumn{2}{c}{ Aman } & \multicolumn{2}{c}{$\begin{array}{c}\text { Tidak } \\
\text { Aman }\end{array}$} \\
\cline { 2 - 5 } & N & $\mathbf{( \% )}$ & N & $\mathbf{( \% )}$ \\
\hline $\begin{array}{l}\text { Perilaku pekerjaan potensi } \\
\text { bahaya tinggi }\end{array}$ & 4 & 75 & 1 & 25 \\
\hline $\begin{array}{l}\text { Perilaku ketika persiapan } \\
\text { kerja }\end{array}$ & 4 & 100 & - & - \\
\hline Perilaku aman pekerja & 9 & 100 & - & - \\
\hline Perilaku operator & 10 & 91 & 1 & 9 \\
\hline Perilaku pelaksana & 9 & 100 & - & - \\
\hline $\begin{array}{l}\text { Perilaku terhadap } \\
\text { penggunaan APD dan }\end{array}$ & 7 & 70 & 3 & 30 \\
\begin{tabular}{l} 
Housekeeping \\
\hline
\end{tabular} & & & & \\
\hline
\end{tabular}

Total nilai perilaku keselamatan yakni sebagai berikut:

Rumus untuk menghitung persentase perilaku aman:

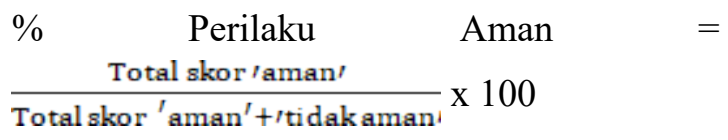

(Tarwaka, 2015) 
Perilaku Aman $=\frac{41}{47} \times 100=87,2 \%$

Maka berdasarkan rumus menghitung persentase perilaku aman menurut (Tarwaka 2015) nilai perilaku aman yang diperoleh PT. $\mathrm{X}$ pada unit produksi spun pile adalah $87,2 \%$. Hasil persentase perilaku aman PT.X pada unit produksi spun pile dikategorikan baik berdasarkan pembagian kategori persentasi perilaku aman menurut (Geller 2001). Maka, perilaku aman pekerja spun pile di PT.X Plant Cibitung baik.

Perilaku Keselamatan (safety behavior) adalah perilaku kerja yang relevan dengan keselamatan dapat dikonseptualisasikan dengan cara yang sama dengan perilakuperilaku kerja lain yang membentuk perilaku kerja. Perilaku keselamatan merupakan aplikasi dari perilaku tugas yang ada di tempat kerja (Griffin \& Neal, 2000). Keselamatan berbasis perilaku pekerja telah menjadi salah satu bidang utama penelitian manajemen keselamatan, karena perilaku tidak aman pekerja memiliki dampak yang signifikan terhadap kinerja produksi ( $\mathrm{Li} \&$ Long, 2019). Berdasarkan hasil penelitian menunjukkan bahwa ada hubungan positif yang signifikan antara iklim keselamatan dan perilaku keselamatan (Chan et al., 2017).

Pada awal tahun 1970 muncul pandangan baru tentang keselamatan kerja yaitu Behavior Based Safety (BBS). Behavior Based Safety (BBS) merupakan aplikasi sistematis dari riset psikologi tentang perilaku manusia pada masalah keselamatan (safety) ditempat kerja. BBS lebih menekankan aspek perilaku manusia terhadap terjadinya kecelakaan ditempat kerja dengan memasukkan proses umpan balik secara langsung dan tidak langsung. Sebuah hasil penelitian menunjukan bahwa perilaku unsafe action karyawan menurun setelah dilakukannya intervensi perilaku keselamatan (Jadidi et al., 2019).
Berdasarkan penelitian Cooper (2006) menjelaskan bahwa komitmen manajemen penting pada kinerja perilaku keselamatan menjelaskan bahwa pemantauan berbasis perilaku menggunakan sistem observasi perilaku berisiko dan kondisi tidak aman dan keamanan berbasis observasi proses pemantauan kepatuhan yang dapat menunjukkan tingkat kepatuhan dengan keamanan yang ditentukan dan disepakati dengan baik. Hasil sebuah penelitian menunjukkan bahwa ada hubungan positif yang signifikan antara iklim keselamatan dan perilaku keselamatan (Chan et al., 2017).

Hasil penelitian menunjukkan bahwa skor perilaku keselamatan secara signifikan lebih tinggi pada pasca-intervensi. Hasil juga menunjukkan bahwa dalam kelompok intervensi, karyawan yang mengalami perubahan yang lebih positif pada prosedur kerja serta sikap dan tindakan positif supervisor mereka terhadap intervensi mengalami perilaku keselamatan pasca intervensi yang lebih tinggi. Berdasarkan hasil penelitian tersebut menunjukkan strategi intervensi berguna untuk perilaku keselamatan (Bronkhorst et al., 2018). Pelaksanaan program pemantauan perilaku berdampak postitif pada budaya keselamatan (Aburumman et al., 2019).

\section{Kesimpulan}

Berdasarkan hasil penelitian dapat disimpulkan bahwa bahwa nilai aman terendah indikator perilaku keselamatan pada pekerja spun pile PT.X yaitu perilaku terhadap penggunaan APD dan housekeeping dengan persentase $70 \%$ aman sedangkan $30 \%$ tidak aman. Faktor budaya keselamatan dengan persentase kesesuaian terendah pada indikator keterlibatan pekerja sebanyak $55,6 \%$ sedangkan $22,2 \%$ tidak sesuai dan $22,2 \%$ tidak ada.

Peneliti selanjutnya dapat melakukan penelitian terkait penilaian atau pengukuran 
penerapan budaya keselamatan (safety culture) di PT. X Plant Cibitung serta dapat melakukan penelitian terkait kepatuhan perilaku keselamatan (safety behavior) serta partisipasi terhadap program pemantauan perilaku keselamatan di PT. X Plant Cibitung.

\section{BIBLIOGRAFI}

Aburumman, M., Newnam, S., \& Fildes, B. (2019). Evaluating the effectiveness of workplace interventions in improving safety culture: A systematic review. Safety Science, 115, 376-392.

Andi, Alifen, \& Chandra. (2005). Model Persamaan Struktural Pengaruh Budaya Keselamatan Kerja pada Perilaku Pekerja di Proyek Konstruksi. Jurnal Teknik Sipil, 12(3), 127-136.

Andini, R. T. (2017). Hubungan Antara Faktor Budaya Keselamatan Kerja dengan Kecelakaan Kerja Pada Karyawan Bagian Produksi PT. Kunango Jantan.

Anizar. (2009). Teknik Keselamatan dan Kesehatan Kerja di Industri. Graha Ilmu.

Aprilia, I. (2017). Hubungan Budaya Keselamatan dan Kesehatan Kerja (K3) terhadap Perilaku Tidak Aman Pada Pekerja Bagian Panen PT. X Kabupaten Mempawah.

Ardi, Hariyono, S. Z., \& Widodo. (2018). Analisa Penerapan Budaya Perilaku Keselamatan dan Kesehatan Kerja di Rumah Sakit. Kes Mas : Jurnal Fakultas Kesehatan Masyarakat, 12(1), 15-20.

Bronkhorst, B., Tummers, L., \& Steijn, B. (2018). Improving safety climate and behavior through a multifaceted intervention: Results from a field experiment. Safety Science, 103, 293 304.

Chan, A., Javed, A., Wong, F., Hon, C., \&
Lyu, S. (2017). Evaluating the Safety Climate of Ethnic Minority Construction Workers in Hong Kong. Journal of Professional Issues in Engineering Education and Practice, 143.

Christina, \& Al, E. (2012). Pengaruh Budaya Keselamatan dan Kesehatan Kerja Terhadap Kinerja Proyek Konstruksi. 6(1), 83-95.

Cooper, M. D. (2000). Towards a model of safety culture. Safety Science, 36(2), 111-136.

Fridayanti, N., \& Kusumasmoro, R. (2016). Penerapan Keselamatan Dan Kesehatan Kerja Di PT Ferron Par Pharmaceuticals Bekasi. Jurnal Administrasi Kantor, 4(1), 211-234.

Geller. (2001). The Psychology Of Safety Handbook. CRC Press LLC.

Griffin, M. A., \& Neal, A. (2000). Perceptions of safety at work: a framework for linking safety climate to safety performance, knowledge, and motivation. Journal of Occupational Health Psychology, 5(3), 347-358.

Harnanda, R. (2017). Hubungan Iklim Keselamatan Kerja Dengan Perilaku Keselamatan Pada Karyawan Bagian Produksi PT. Cahaya Murni Andalas Permai Padang.

Jadidi, E., Borgheipour, H., \& Mohammadfam, I. (2019). The Effect of Behavior-based Safety Interventions on the Reduction of Unsafe Behavior. Archives of Occupational Health, 3.

Jiang, W., Liang, C., \& Han, W. (2019). Relevance Proof of Safety Culture in Coal Mine Industry. International Journal of Environmental Research and Public Health, 16(5).

Kania, Dewi, D., Probo, Eko, \& Hanifah. (2016). Analisis Faktor Budaya Keselamatan dan Kesehatan Kerja (K3) 
pada Penanganan Kargo di Bandara Soekarno Hatta International Airport. Manajeman Transportasi Dan Logistik, $3(1), 1-13$.

Ketenagakerjaan, B. P. J. S. (2019). Laporan Data Kecelakaan Kerja 2019.

Khoiri, M. (2010). Upaya Peningkatan Budaya Keselamatan Pekerja Radiasi Rumah Sakit di Indonesia. Seminar Nasional IV SDM Teknologi Nuklir, 571-576.

Li, X., \& Long, H. (2019). A Review of Worker Behavior-Based Safety Research: Current Trends and Future Prospects. IOP Conference Series: Earth and Environmental Science, 371, 32047.

Nascimento, C. F., \& Frutuoso E Melo, P. F. F. (2010). A behavior- and observationbased monitoring process for safety management. International Journal of Occupational Safety and Ergonomics: JOSE, 16(4), 407-420.

Nordlöf, H., Wiitavaara, B., Högberg, H., \& Westerling, R. (2017). A cross-sectional study of factors influencing occupational health and safety management practices in companies. Safety Science, 95(June), 92-103.

Nurhayati, D. (2018). Hubungan Antara Faktor Pembentuk Budaya Keselamatan Kerja dengan Safety Behaviour pada Pekerja di PT. Pertamina (Persero) Terminal BBM Banjarmasin Tahun 2018. Fakultas Kesehatan Masyarakat UNISKA Banjarmasin, 1-7.

Qayoom, A., \& Hadikusumo, B. (2019). Multilevel safety culture affecting organization safety performance: a system dynamic approach. Engineering, Construction and Architectural Management, ahead-of-p.
Shehu Mashi, M., Subramaniam, C., \& Johanim, J. (2018). The effect of management commitment to safety, and safety communication and feedback on safety behavior of nurses: the moderating role of consideration of future safety consequences. The International Journal of Human Resource Management, 31, 1-30.

Somad, I. (2013). Teknik Efektif dalam Membudayakan Keselamatan dan Kesehatan Kerja. Dian Rakyat.

Sutrisno, Yudha, H., Sandora, Rina, Rachman, \& Farizi. (2017). Pengaruh Iklim Keselamatan terhadap Perilaku Keselamatan pada Proyek Tol SurabayaMojokerto Seksi 1B. Proceeding 1st Conference on Safety Engineering and Its Aplication, 19-23.

Suyono, K. Z., \& Nawawinetu, E. D. (2013). Hubungan Antara Faktor Pembentuk Budaya Keselamatan Kerja Dengan Safety Behaviour di PT DOK dan Perkapalan Surabaya Unit Hull Construction. The Indonesian Journal of Occupational Safety and Health, 2(1), 67-74.

Tarwaka. (2015). Keselamatan dan Kesehatan Kerja dan Ergonomi (K3E) dalam Perspektif Bisnis. Harapan Press.

Tehrani, V., Rezaifar, O., Gholhaki, M., \& Khosravi, Y. (2019). Investigating Factors of Safety Culture Assessment in Construction Industry Projects. Civil Engineering Journal, 5, 971-983.

Utami, Y. T. (2016). Hubungan Antara Faktor-Faktor Budaya Keselamatan (Safety Culture) dengan Perilaku Keselamatan (Safety Behaviour) pada Karyawan Pemanen Kelapa Sawit PT. Tidar Kerinci Agung Solok Selatan Tahun 2016. 